A.S. Lynch, E. Sonnhammer, and R. Durbin. 1996. The C. elegans expression pattern database: a beginning. Trends Genet. 12:370-371

8.Lynch, A.S., D. Briggs, and I.A. Hope. 1995. Developmental expression pattern screen for genes predicted in the $C$. elegans genome sequencing project. Nat. Genet. 11:309-313.

9.McPherson, M.J., P. Quirke, and G.R. Taylor. 1992. PCR: A Practical Approach, Oxford University Press, Oxford.

10.Mello, C.C., J.M. Kramer, D. Stinchcomb, and V. Ambros. 1991. Efficient gene transfer in C. elegans: extrachromosomal maintenance and integration of transforming sequences. Embo J. 10:3959-3970.

11.Troemel, E.R., J.H. Chou, N.D. Dwyer, H.A. Colbert, and C.I. Bargmann. 1995. Divergent seven transmembrane receptors are candidate chemosensory receptors in C. elegans. Cell 83:207-218.

12.White, B.A. 1993. PCR Protocols. Current Methods and Applications. Humana Press, Totowa, NJ.

13.Young, J.M. and I.A. Hope. 1993. Molecular markers of differentiation in Caenorhabditis elegans obtained by promoter trapping. Dev. Dyn. 196:124-132.

14.Zhang, M.Q. 1999. Promoter analysis of coregulated genes in the yeast genome. Comput. Chem. 23:233-250.

I am grateful to Stephen Nurrish for the exchange of ideas, Gary Ruvkun, in whose laboratory I first used this technique, Andy Fire for pPD95.75, and members of my own laboratory, in particular Oscar Aurelio, for repeated use and validation of the technique. Work in my laboratory is funded by a grant from the National Institutes of Health (NS399996-02), the March of Dimes, Whitehall, Searle, Klingenstein, Sloan, Rita Allen, and Irma T. Hirschl Foundations. Address correspondence to Dr. Oliver Hobert, Department of Biochemistry and Molecular Biophysics, Center for Neurobiology and Behavior, Columbia University, College of Physicians and Surgeons, New York, NY 10032,USA.e-mail: or38@columbia.edu

Received 14 November 2001; accepted 18 January 2002.

\section{Oliver Hobert}

Columbia University

New York, NY, USA

For reprints of this or any other article, contact Reprints@BioTechniques.com
Partial Heat Denaturation Step during Reverse Transcription and PCR Screening Yields FullLength $5^{\prime}$-cDNAs

\section{BioTechniques 32:730-736 (April 2002)}

RNA secondary and tertiary structures, such as hairpins, stem-loop structures, or even more complicated arrangements like bifurcations and triple-helical elements, play an important role in mRNA stability, RNA processing, and translation efficiency (5). The stability of some of these structural elements often compromises the synthesis of full-length cDNAs (Figure 1). This report describes an intermediate partial heat denaturation step during reverse transcription, followed by the addition of fresh enzyme, which overcomes the problem of reverse transcriptase stoppage. This step is performed at $85^{\circ} \mathrm{C}$, which does not allow the perfectly matching RNA-DNA hybrids to denature, whereas potential RNA secondary structures are more likely to melt (Figure 1D). Utilizing this protocol, markedly more fulllength cDNAs were recovered compared to other approaches that aim to overcome RNA secondary structures, such as those that use (i) the thermostable $r$ Th DNA polymerase (Perkin Elmer, Weiterstadt, Germany) that allows reverse transcription of mRNAs at $68^{\circ} \mathrm{C}$, or (ii) performing reverse transcription at $55^{\circ} \mathrm{C}$ with non-thermostable reverse transcriptases as recommended by the supplier, and (iii) the addition of DMSO [e.g., Moloney murine leukemia virus (MMLV) reverse transcriptase; usage information sheet, Promega, Madison, WI, USA]. The procedure was also successfully applied to primer extension analysis. Furthermore, a rapid PCR screening protocol is described for plasmids containing long inserts, allowing the characterization of full length $5^{\prime}$-cDNAs from total RNA within three days. This method was found to be extremely useful for the detection of low-abundance, full-length cDNA fragments in a pool of shorter fragments, which is a fre- quently encountered occurrence when RNA integrity is compromised (i.e., when no fresh tissues are available for RNA preparation) or if the target mRNA is transcribed at low levels in the analyzed tissue.

The partial heat denaturation method was successfully applied to clone a variety of cDNAs from different genes. Here, the described studies focused on the isolation of complete $5^{\prime}$ cDNAs of cytochrome $c$ oxidase subunits from two species. In several cases in the past, the synthesis of full-length sequences failed because of an unusually high $\mathrm{G} / \mathrm{C}$ content in the $5^{\prime}$-region, which probably led to unusually stable mRNA secondary structures. Using the thermostable $r$ Tth DNA polymerase, MMLV reverse transcriptase (AGS, Heidelberg, Germany) and the SuperScript $^{\top \mathrm{M}}$ II reverse transcriptase (Invitrogen, Carlsbad, CA, USA) yielded similar unsatisfactory results in the crucial reverse transcription step using standard protocols.

To obtain full-length cDNA sequences, 3'-rapid amplification of cDNA ends (RACE) PCR was first performed as described by Frohman (2), followed by an optimized 5'-RACE protocol, which is described here. In brief, 3'-RACE PCR utilized a $\mathrm{dT}_{17^{-}}$ tailed oligonucleotide, $\mathrm{Q}_{\mathrm{T}}$-primer $\left(5^{\prime}\right.$ CCAGTGAGCAGAGTGACGAGGACTCGAGCTCAAGC []$_{17^{-3}} 3^{\prime}$ ), to prime the total cDNA first-strand synthesis, either starting from $5 \mu \mathrm{g}$ total RNA or $1 \mu \mathrm{g}$ mRNA. The protocol was identical to the $5^{\prime}$ reverse transcription reaction described below [except that the $\mathrm{Q}_{\mathrm{T}}$-primer is used instead of gene specific primer 1 (GSP1) to prime the cDNA first-strand synthesis]. The appended sequence of the $\mathrm{Q}_{\mathrm{T}}$-primer allowed the utilization of specific primers $\mathrm{Q}_{\text {outer }}$ (5'-CCAGTGAGCAGAGTGA CG-3') and $\mathrm{Q}_{\text {inner }}$ (5'-GAGGACTCGAGCTCAAGC-3') in subsequent outer and nested PCR amplifications. The 3'-cDNAs were obtained by screening the total cDNA population with a first degenerate primer (e.g., derived from an amino acid sequence or a conserved region from known sequences of other species) using $\mathrm{Q}_{\text {outer }}$ as counter primer in a standard $50-\mu \mathrm{L}$ reaction. A nested PCR was performed similarly to increase specificity, using 1 
$\mu \mathrm{L}$ of a 1:100 dilution of the preceding reaction, and a second (nested) primer along with $\mathrm{Q}_{\text {inner }}$ The amplified PCR fragments could be directly sequenced or cloned and sequenced if there was more than one gel band.
The following protocol is provided for the use of the SuperScript II reverse transcriptase but can be applied analogously utilizing any other reverse transcriptase. For 5'-RACE PCR, three reverse gene-specific primers (GSPs; $T_{m}$
A

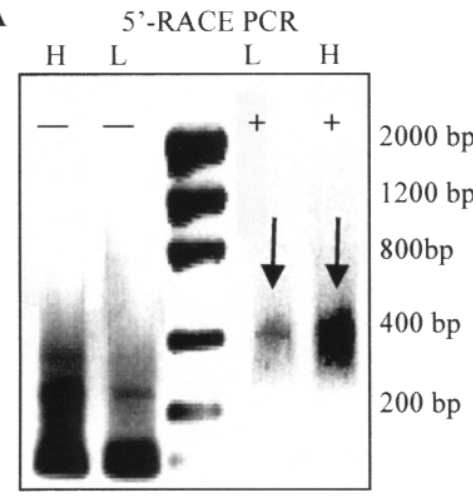

D
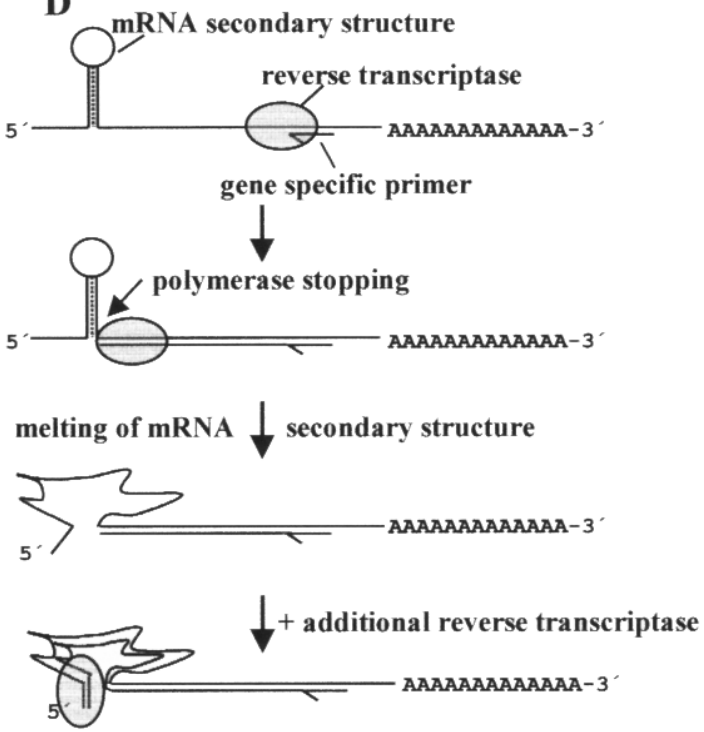

full-length 5 -cDNAs
B
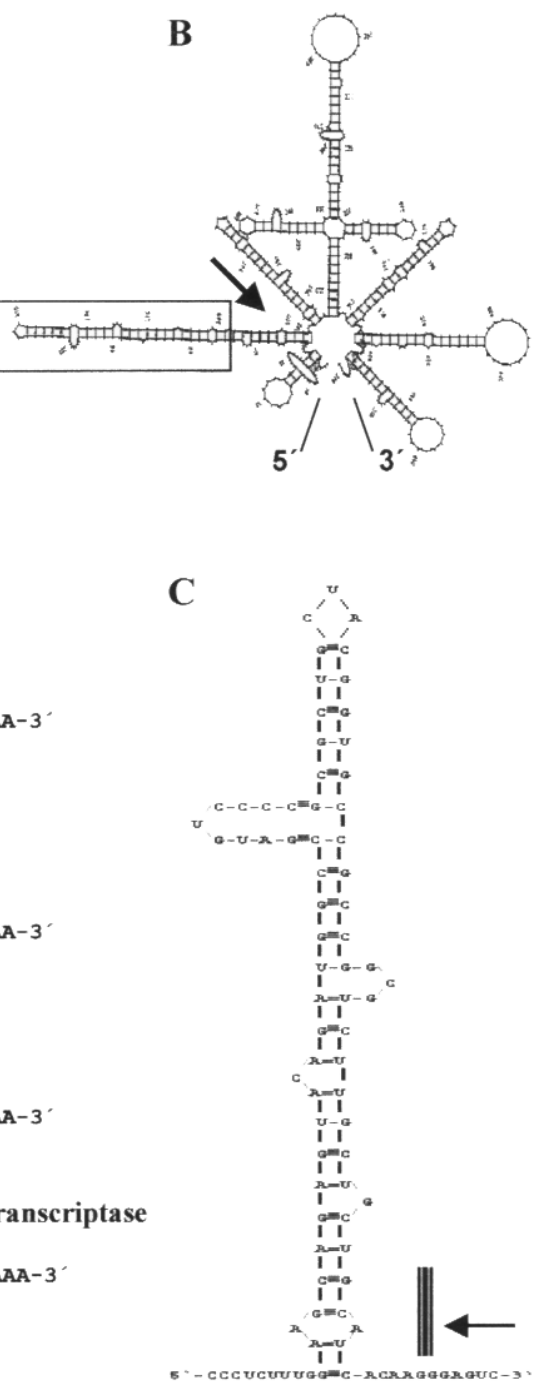

Figure 1. Stable mRNA secondary structures often compromise full-length cDNA synthesis but can be overcome with a partial heat denaturation step. (A) $5^{\prime}$-cDNA synthesis of COX subunit VIa from carp yielded mostly truncated PCR fragments, using standard protocols for reverse transcription (left two "-" lanes), whereas the performance of the partial heat denaturation step allowed the synthesis of fulllength 5'-cDNAs (right two "+" lanes, arrows), starting from heart $(\mathrm{H})$ or liver $(\mathrm{L})$ tissue. Shown is the nested PCR amplification, separated on a 1.2\% agarose gel, and stained with ethidium bromide. (B) The program MFold (Dr. M. Zuker, Rensselaer Polytechnic Institute, Troy, NY, USA) was used to predict the 50 most stable secondary structures for the obtained sequence (GenBank ${ }^{\circledR}$ accession no. U83907). Shown is the most stable calculated secondary structure, including a stem element (box) that was found in all calculated structures (magnified in panel C), which could not be overcome by the reverse transcriptase (arrow in parts B and C) during cDNA first-strand synthesis using standard protocols. The fragment size of the truncated major PCR product (panel A, left two lanes) corresponds to the "DNA polymerase stopping" at the indicated site. (D) Schematic diagram of the optimized $5^{\prime}$ reverse transcription. Performance of the partial heat denaturation step during reverse transcription allows the freshly added reverse transcriptase to copy newly denatured regions, yielding full-length $5^{\prime}$-RACE PCR fragments.

is approximately $60^{\circ} \mathrm{C}$ ) were derived from the known $3^{\prime}$-RACE sequence of cytochrome c oxidase subunit VIa from carp (4). The following mixture was prepared in a thin-walled $0.5-\mathrm{mL}$ PCR tube: $5 \mu \mathrm{g}$ total RNA (or $1 \mu \mathrm{g}$ mRNA), $0.5 \mu \mathrm{L}$ RNase inhibitor ( $40 \mathrm{U} / \mu \mathrm{L}$; Stratagene, La Jolla, CA, USA), $5 \mu \mathrm{L}$ dNTPs ( $2 \mathrm{mM}$ each), $1 \mu \mathrm{L}$ of the outermost GSP1 $(10 \mu \mathrm{M})$, RNase-free water to a $15 \mu \mathrm{L}$ final volume. The starting amount of total RNA can be scaled down to $0.1-0.5 \mu \mathrm{g}$ if the target mRNA is transcribed in the tissue used for RNA isolation. The contents of the tube were mixed by pipetting. The tube was heated to $80^{\circ} \mathrm{C}$ for $3 \mathrm{~min}$ and immediately put in an ice-water slurry for $2 \mathrm{~min}$, which reduces the formation of highly stable RNA secondary structures. Following this, $5 \mu \mathrm{L} 5 \times$ first-strand buffer (Invitrogen), $2.5 \mu \mathrm{L}$ DTT, and $1.5 \mu \mathrm{L}$ reverse transcriptase $(200 \mathrm{U} / \mu \mathrm{L})$ were added, mixed by pipetting, and incubated at $37^{\circ} \mathrm{C}$ for $90 \mathrm{~min}$. The mixture was heated to $85^{\circ} \mathrm{C}$ for $3 \mathrm{~min}$ and immediately put in an ice-water slurry for $2 \mathrm{~min}$. The reverse transcription was continued by adding a $1 \mu \mathrm{L}$ reverse transcriptase, followed by another $60-$ min incubation at $37^{\circ} \mathrm{C}$. The integration of this partial heat denaturation step clearly increased the amount of full-length transcripts produced, which, for several sequences, could not be obtained at all using standard protocols (Figure 1). Reverse transcriptase was then heat-inactivated at $75^{\circ} \mathrm{C}$ for $10 \mathrm{~min}$, followed by RNA degradation through adding $1 \mu \mathrm{L}$ RNase $\mathrm{H}(2 \mathrm{U} / \mu \mathrm{L}$; Invitrogen), incubation at $37^{\circ} \mathrm{C}$ for $20 \mathrm{~min}$, and heat inactivation at $75^{\circ} \mathrm{C}$ for $10 \mathrm{~min}$. To separate the cDNA first strands from dNTPs, NTPs, salts, and primers, $100 \mu \mathrm{L}$ T-buffer $(10 \mathrm{mM}$ Tris, $\mathrm{pH}$ 8.0) were added to the cDNA first-strand solution, transferred to a Microcon $^{\mathrm{TM}}$ YM-30 tube (Millipore, Bedford, MA, USA), and centrifuged for 10 $\min$ at $10000 \times g$. The DNA was washed twice by adding $200 \mu \mathrm{L}$ T-buffer into the YM-30 tube and centrifuged as described above. To recover the cDNA first strands, the YM-30 concentrator was inverted and then inserted into a new tube, and $8-10 \mu \mathrm{L}$ remaining liquid were collected by centrifugation for 5 $\min$ at $14000 \times g$ and brought to a final volume of $12 \mu \mathrm{L}$ with water. To append a poly-A tail to the $3^{\prime}$-end of the cDNAs 
(which corresponds to the $5^{\prime}$-end of the mRNAs), $3 \mu \mathrm{L}$ dATP (1 mM), $4 \mu \mathrm{L} 5 \times$ reaction buffer (USB, Bad Homburg, Germany), and $1 \mu \mathrm{L}$ terminal desoxynucloetidyl transferase $(14 \mathrm{U} / \mu \mathrm{L}$; USB) were added. Incubation was performed for no longer than $3 \mathrm{~min}$ at $37^{\circ} \mathrm{C}$ to avoid the formation of unnecessary long poly-A tails, followed by heat inactivation of the enzyme as described above. Second-strand synthesis and outer PCR (see Figure $2 \mathrm{~A}$ for primer locations) were performed as a one-tube $50-\mu \mathrm{L}$ standard reaction, including the $\mathrm{Q}_{\mathrm{T}}$-pri$\operatorname{mer}(1 \mu \mathrm{L} ; 10 \mu \mathrm{M})$, the $\mathrm{Q}_{\text {outer }}$-primer, and the next inner GSP2 $(1.5 \mu \mathrm{L}$ each; $10 \mu \mathrm{M})$ : Denaturation at $94^{\circ} \mathrm{C}$ for $2 \mathrm{~min}$, annealing of the dT17-part of the QTprimer to the poly-A tail of the cDNA first strands at $38^{\circ} \mathrm{C}$ for $3 \mathrm{~min}, 5 \mathrm{~min}$ ramp from $38^{\circ} \mathrm{C}$ to $72^{\circ} \mathrm{C}$, and extension at $72^{\circ} \mathrm{C}$ for $5 \mathrm{~min}$. The second-strand synthesis was then completed and directly followed by the outer PCR, where primers $Q_{\text {outer }}$ and GSP2 act for 32 cycles at $94^{\circ} \mathrm{C}$ for $40 \mathrm{~s}$ (denaturation), $59^{\circ} \mathrm{C}$ for $30 \mathrm{~s}$ (annealing), and $72^{\circ} \mathrm{C}$ for $1 \mathrm{~min}$ (extension). To increase specificity, a nested PCR was performed using $\mathrm{Q}_{\text {inner }}$ and the most inner GSP3 primers with $1 \mu \mathrm{L}$ of a 1:100 dilution of the previous reaction as template. After running an agarose gel, appropriate bands (mostly smeared) were excised $50 \mathrm{bp}$ above their highest intensity to favor the recovery of the longest cDNAs. Fragments were gel-extracted and cloned into a vector [e.g., pBluescript ${ }^{\circledR}$ SK$^{-}$ (Stratagene) or pGEM-T ${ }^{\circledR}$ Easy (Promega)]. PCR fragments were directly sequenced when robust amplifications of the expected size were obtained.

The inclusion of the partial heat denaturation step clearly improved the synthesis of full-length $5^{\prime}$-cDNAs for COX VIa from carp, starting from either heart or liver total RNA (Figure $1 \mathrm{~A}$, two right lanes). The structural prediction analysis of the mRNA sequence revealed a secondary structure element (Figure 1, B and C), which could not be overcome by the reverse transcriptase using a standard protocol. RNA secondary structures and their melting profiles have been widely studied, mostly for ribosomal RNA and tRNA species. Depending on the concentration of mono and bivalent cations and the intrinsic strength of the RNA secondary structure, a broad temperature range was found to melt individual structural elements. Importantly, these studies revealed that the $T_{m}$ even for the strongest elements was $85^{\circ} \mathrm{C}$ or was already exceeded at this temperature (1). The $T_{m}$ of the 375-bp sequence from the 3 '-end of the carp COX VIa cDNA up to the $5^{\prime}$-site where the DNA polymerase stopping was observed was calculated to be $85^{\circ} \mathrm{C}$ for a DNA-DNA hybrid at $50 \mathrm{mM}$ monovalent cation concentration (IDT'S OLIGO ANALYZER software; www.idtdna.com). Furthermore, perfectly matching RNADNA hybrids, as present in the nascent mRNA-cDNA hybrid show a high thermal stability that is clearly superior to DNA (6), supporting the initial hypothesis that the already synthesized cDNA stays attached to the mRNA during the partial heat denaturation step. The formation of the identical secondary structure element after the partial heat denaturation step is probably prevented because of the already synthesized cDNA first strand adjacent to it.

A rapid PCR screening protocol was successfully used that allowed the isolation of full-length $5^{\prime}$-cDNA fragment-containing clones from the vastly more numerous truncated fragments, despite initiating $5^{\prime}$-RACE using partially degraded RNA (derived from tissue, not directly frozen after excision), or starting from tissues where the target sequences are not transcribed at a high level (Figure 2B). In the given example, standard RACE protocols did not yield a single full-length fragment in 300 clones. Three different degraded tuna tissues (muscle, liver, and heart) were

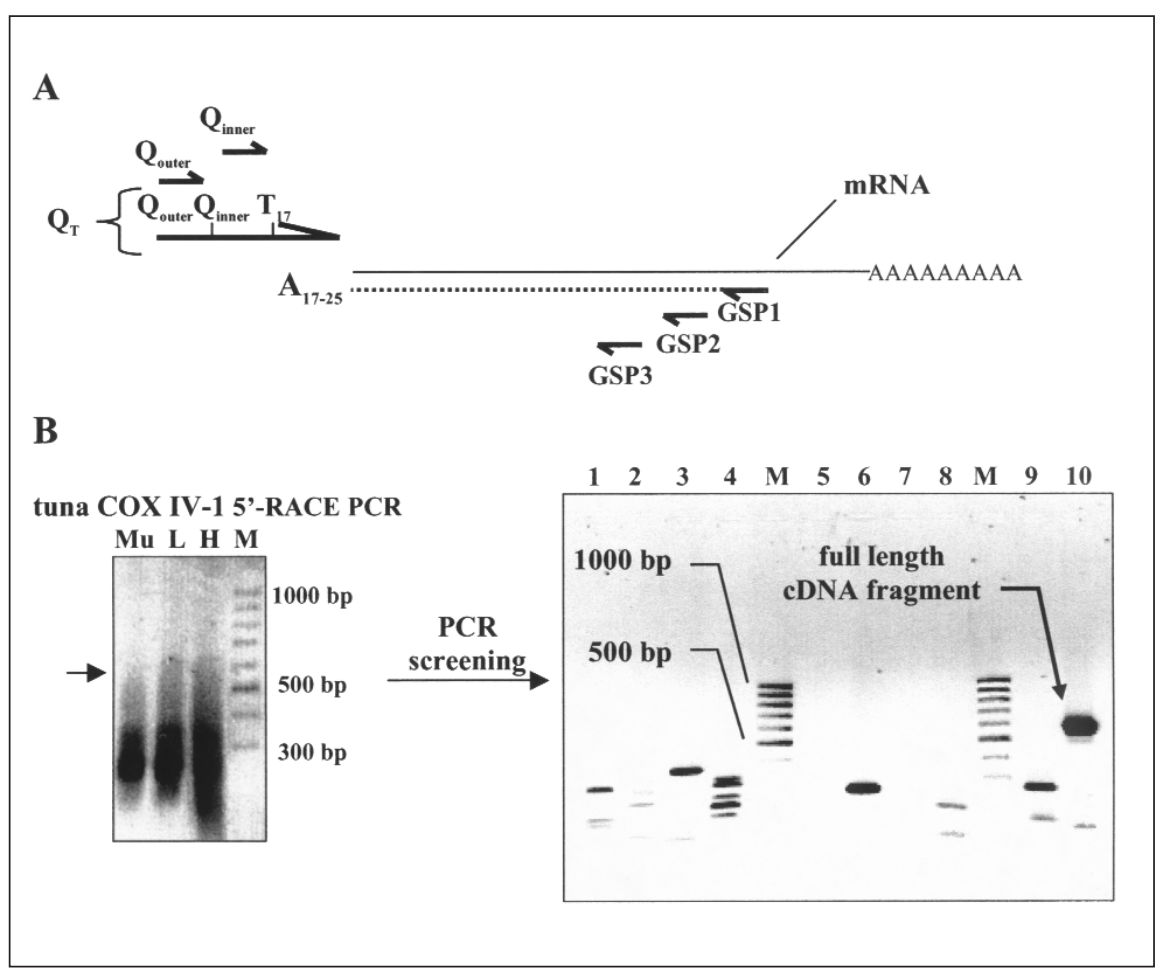

Figure 2. Screening for full-length cDNAs among the vast majority of truncated fragments. (A) Schematic representation of the primers used for $5^{\prime}$-RACE PCR. GSP1 was utilized to generate cDNA first strands (dotted line) from the mRNA template. A poly-A tail $\left(\mathrm{A}_{17-25}\right)$ was appended to the $3^{\prime}$-end of the cDNA first strands, which served to anneal the $\mathrm{Q}_{\mathrm{T}}$ primer, followed by the second-strand synthesis. Primer pairs $\mathrm{Q}_{\text {outer }}$ and GSP2 and $\mathrm{Q}_{\text {inner }}$ and GSP3 were used subsequently for outer PCR and nested PCR. (B) Partially degraded RNA from tuna muscle (Mu), liver (L), and heart $(\mathrm{H})$ were used as template for 5'-RACE PCR to isolate the COX IV-1 full-length 5'-cDNA (DNA-Bio-Ladder ${ }^{\mathrm{TM}}$ 100; AGS, Heidelberg, Germany). The nested PCR of the 5'-RACE shows a smeared amplification for all tissues, with almost no detectable signal in the expected size range (arrow, left gel). A gel band was excised in the expected fragment size of the heart amplification and cloned. Thirty colonies were combined in each tube to screen for a long fragment in 10 individual reactions. One 600-bp fragment was obtained, whereas all other bands are clearly shorter (right gel). The fragment was excised and directly sequenced after DNA purification, revealing the correct sequence. 
available to isolate the full-length $5^{\prime}$-sequence of a new isoform of cytochrome $c$ oxidase subunit IV (3) that was only transcribed in low amounts in the available tissues, as was later confirmed by quantitative PCR.

After 5'-RACE PCR was completed, the PCR products consisted almost exclusively of truncated fragments (Figure 2B, left gel), clearly smaller in size than expected. Therefore, bands for DNA extractions were excised in the expected size range (Figure 2B, left gel, arrow), even if no DNA was visible in that region after ethidium bromide staining, and cloned. Because of the poor separation properties of agarose gels, most of the isolated DNA represented the main (truncated) PCR products. To circumvent the onerous search for full-length clones by analyzing many individual plasmids, 300 insert-containing colonies were directly PCR-screened in 10 individual reactions. For each reaction, 30 colonies were picked (about half of the cellular mass), combined in $300 \mu \mathrm{L}$ of double-distilled water, and mixed. Cells were cracked in the open tubes with two 20-s microwave pulses, and 1 $\mu \mathrm{L}$ of this solution was used without further purification as template in a $\mathrm{PCR}$, utilizing the gene specific innermost primer and $\mathbf{Q}_{\text {inner }}$ under similar conditions as described above for the nested PCR. The observed band pattern in the subsequent agarose gel revealed mainly truncated fragments except for one band of the expected size (Figure 2, right gel, arrow). This band was excised, the DNA isolated, and directly sequenced with the gene-specific primer and $\mathrm{Q}_{\text {inner, }}$, showing the full-length 5'region of the tuna COX IV- 1 cDNA (AF204870), including 34 bp of 5'-untranslated region.

In summary, these protocols allow the rapid characterization of full-length cDNAs, despite the presence of mRNA secondary structures, partially degraded template RNA, or tissue with low expression levels of the target cDNA.

\section{REFERENCES}

1.Draper, D.E. and T.C. Gluick. 1995. Melting studies of RNA unfolding and RNA-ligand interactions. Methods Enzymol. 259:281-305.

2.Frohmann, M.A. 1995. Rapid amplification of cDNA ends, p. 381-409. In C.W. Dieffen- bach and G.S. Dveksler (Eds.), PCR Primer: A Laboratorial Manual. CSH Laboratory Press, Cold Spring Harbor, NY.

3.Hüttemann, M. 2000. New isoforms of cytochrome $c$ oxidase subunit IV in tuna fish. Biochim. Biophys. Acta 1492:242-246.

4.Hüttemannn, M., S. Exner, and B. Kadenbach. 1997. The cDNA sequences of cytochrome $c$ oxidase subunit VIa from carp and rainbow trout suggest the absence of isoforms in fishes. Biochim. Biophys. Acta 1319:14-18.

5.Klaff, P., D. Riesner, and G. Steger. 1996. RNA structure and regulation of gene expression. Plant. Mol. Biol. 32:89-106.

6.Wegnez, M. and H. Denis. 1970. [Fusion points of DNA-RNA hybrid molecules.] Biochim. Biophys. Acta 204:617-619.

This project was supported by Drs. B. Kadenbach and S. Exner, Philipps University, Marburg, Germany. Thanks to Dr. L. Grossman, Dr. D. Wildman, and A. Goldberg for critical suggestions on the manuscript. Address correspondence to Dr. Maik Hüttemann, Center for Molecular Medicine and Genetics, Wayne State University School of Medicine, Detroit, MI 48201, USA.e-mail: maik@genetics.wayne.edu

Received 25 July 2001; accepted 21 January 2002.

Maik Hüttemann

Wayne State University

School of Medicine

Detroit, MI, USA

For reprints of this or any other article, contact Reprints@BioTechniques.com

\section{Chimeric Gene Construc- tion without Reference to Restriction Sites}

BioTechniques 32:736-740 (April 2002)

Sequence databases now abound with open reading frames related to gene products of known function. Functional analysis of the numerous "homologs" undoubtedly will involve various chimeric constructs between the characterized gene product and the unknown open reading frame. Traditionally, the exchange has been performed by cutting out a segment from the donor DNA, using restriction sites common to the two genes, and ligating it into the recipient DNA. However, more often than not, such convenient restriction sites are not available, and chimeras are sometimes constructed with great ingenuity (1). One way to overcome this challenge is to engineer a restriction site by site-directed mutagenesis, but because convenient sequences must be found for the alterations, the precise manipulation of DNA is not always possible.

Here we present a universal method to exchange practically any segment of two homologous sequences without regard to restriction sites. Toward that end, we take full advantage of the unique properties of Class IIS restriction enzymes. By employing our new method, only two to four nucleotide homologies are necessary to exchange segments between genes, with no requirement for common restriction sites.

Class IIS restriction enzymes recognize non-palindromic sequences, and cleave at sites that are separate from their recognition sequences $(2,3,7)$. The latter trait gives Class IIS enzymes two useful properties. First, when a Class IIS enzyme recognition site is engineered at the end of a primer, the site is cleaved off when digested. Second, overhangs created by Class IIS enzymes are template-derived and thus unique. This is in clear contrast to regular Class II restriction enzymes such as EcoRI, which creates an enzyme-defined overhang that ligates to any EcoRI-digested end. The unique overhangs produced by Class IIS enzymes can be ligated only to their original partner. 